\title{
A Highly Stable Electronic Integrator for Solar Radiation Measurements
}

\author{
Duane H. Turner \\ Atmospheric Turbulence and Diffusion Laboratory, ESSA, Oak Ridge, Tenn. \\ 6 August 1965 and 11 August 1966
}

\section{Introduction}

A solar radiation integrator has been designed, built and tested at this laboratory. The following design specifications were imposed :

a) simplicity of construction and maintenance; b) accuracy of 99 per cent or better;

c) no mechanical coupling to an existing recorder;

d) no significant loss of calibration of a Leeds and Northrup (L\&N) strip chart recorder when the integrator and recorder are connected to a common pyranometer;



FIG. 1. Wiring diagram of solar radiation integrator. Unless otherwise noted, $\frac{1}{2} \mathrm{~W}$ composition resistors are used. 


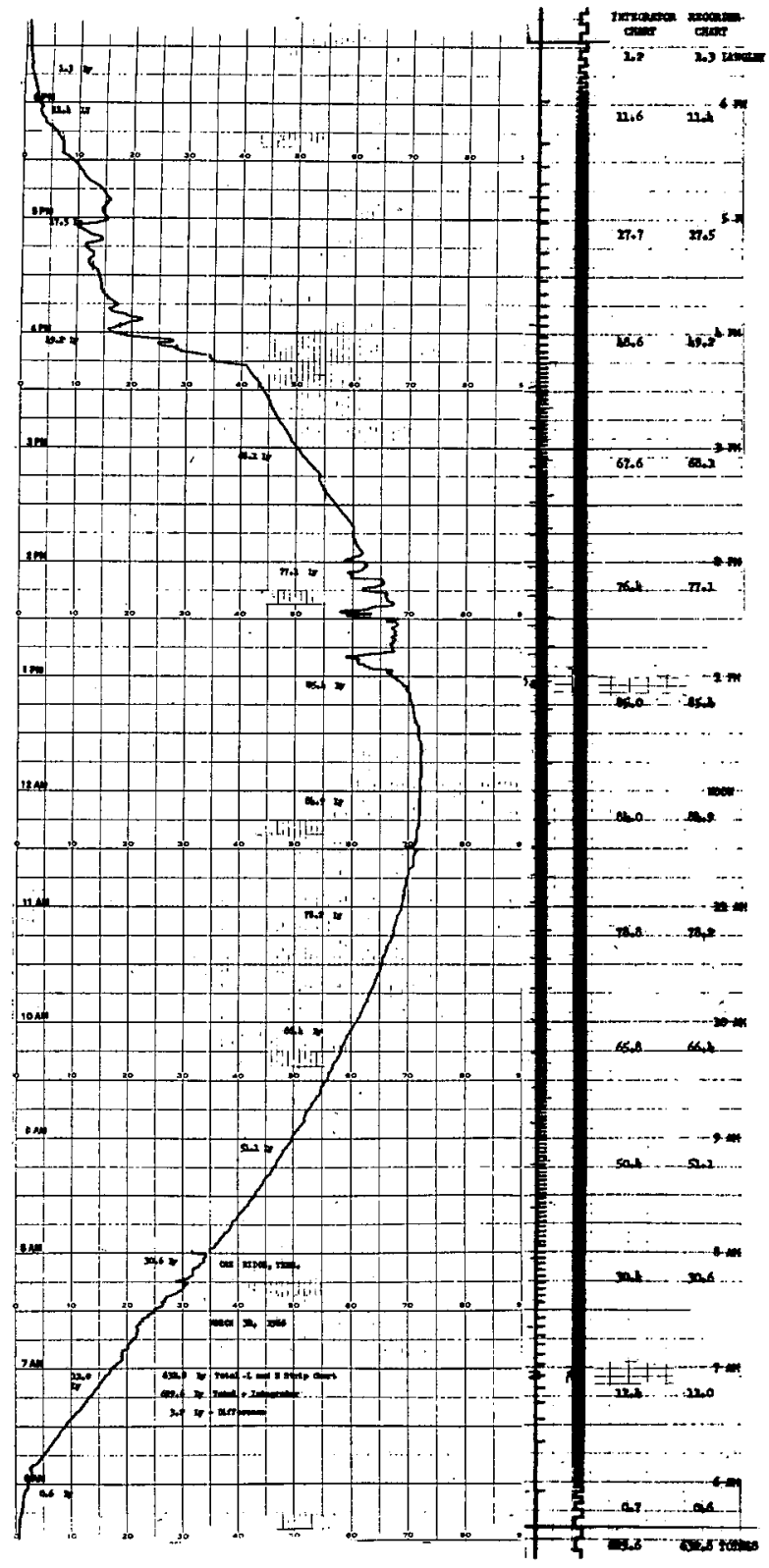

FIG. 2. Integrator and L\&N charts for 31 March 1966.

e) routine checking of calibration not required more often than once a month;

f) no requirement for bias to override the zero drift of the integrating amplifier.

Most (but not all) of these specifications were met by an electronic integrator designed by Thurtell and Tanner (1964).

\section{Description}

Fig. 1 shows the wiring diagram of the Oak Ridge instrument. This integrator differs from the Thurtell and Tanner model chiefly in that it uses two low-drift amplifiers (Weston Model 1411 "Inductronic"), the first to prevent loading the pyranometer output and the second as the integrating amplifier. Two channels of an Esterline-Angus ten-pen recorder are used in conjunction with an electronic counter to produce a record showing one mark for each 2 ly of solar radiation received, as well as one mark (by a second pen) for each 0.2 ly. Input/output count ratios are $20 / 1$ and $2 / 1$. Another counter could be added to permit recording of 20-ly increments with a third pen to facilitate chart reading. Two isolated $(12 \mathrm{~V})$ voltage regulated power supplies are connected between points A, B and C, D. The negative terminal of a third $(32 \mathrm{~V})$ power supply is connected to point $\mathrm{E}$ with the positive terminal connected to point $\mathrm{A}$.

\section{Performance}

During the past year the performance of this integrator has been quite satisfactory, as shown by numerous comparisons of the integrator records with the results of manual integrations of concurrent $L \& N$ potentiometer records. In almost all cases, the two records give results which agree within 1 per cent. Experience has shown that the Weston amplifiers have very little zero drift when ambient room temperatures do not fluctuate more than $\pm 5 \mathrm{C}$. The calibration and zero setting were adjusted only twice during the year. Because of the excessive time required to manually evaluate the potentiometer charts, the two records are now compared only on completely clear days when the potentiometer record can be most accurately evaluated. Fig. 2 gives an example of the records used in such a comparison for 31. March 1966. On this day the L\&N recorder logged a total of $632.8 \mathrm{ly}$ and the integrator $629.6 \mathrm{ly}$, a difference of 0.51 per cent.

Acknowledgments. This work was performed under an agreement between the Environmental Science Services Administration and the U. S. Atomic Energy Commission.

\section{REFERENCE}

Thurtell, G. W., and C. B. Tanner, 1964: Electronic integrator for micrometeorological data. J. Appl. Meteor., 3, 198-202. 